\section{P102 SENESCENCE OF RENAL RESIDENT CELLS IS ASSOCIATED WITH IMPAIRED RENAL FUNCTION IN LUPUS NEPHRITIS}

${ }^{1}$ Gaëlle Tilman, ${ }^{2}$ Selda Aydin, ${ }^{2}$ Christine Galant, ${ }^{1}$ Farah Tamirou, ${ }^{1}$ Frédéric Houssiau, ${ }^{1}$ Bernard Lauwerys. 'Dept. of Rheumatology, Université Catholique de Louvain, Brussels; ${ }^{2}$ Dept. of Pathology, Université Catholique de Louvain, Brussels, Belgium

\subsection{6/lupus-2020-eurolupus. 146}

Background Renal fibrosis is a feared complication of Lupus Nephritis (LN), and is associated with irreversible loss of kidney function. In our previous experiments, we found that intrarenal infiltration by immune effectors in $\mathrm{LN}$ correlates with the development of renal fibrosis. Here, we wondered whether cellular senescence, through its typical secretome (known as senescence-associated secretory phenotype or SASP) or through the accumulation of functionally incompetent cells, are part of the renal functional impairment and fibrotic process in LN.

Methods Microarray data (Illumina HumanHT-2 v4 Expression BeadChip), obtained by our group from 32 human LN kidney biopsies and 8 controls were mined using GeneSpring software in order to study the expression of SASP-associated transcripts. Senescent cells were identified in human LN kidney biopsies using an anti-p16 antibody (Roche Diagnostics). Evaluation of glomerular activity and chronicity indices, glomerular and interstitial fibrosis was performed using conventional or quantitative scores on HE- PAS- and Red Sirius-stained sections. Clinical and biological data were retrieved from the medical files of the patients.

Results Mining of microarray data obtained from 32 LN kidney biopsies indicated that SASP-associated transcripts (e.g. IGFB4, VCAM1, TGFb2, COL1A2, MMP7) were significantly overexpressed in kidney biopsies characterized by the presence of adaptive immune cell infiltrates in the interstitium and lower renal function. Expression of SASP-associated transcripts correlated significantly with the expression of $\mathrm{b}$ galactosidase (GLB1), a key regulator of the senescence process.

In a pilot experiment, we stained LN renal biopsy sections using anti-p16 antibodies, in order to detect the presence of senescent cells. We found a positive stain in podocytes and renal tubular cells from $8 \mathrm{LN}$ patients. The number of positive cells correlated positively with the number of intrarenal CD8-positive cells and the amount of fibrosis in these samples, while it correlated negatively with renal function (eGFR). Conclusion Our data show that the presence of senescent podocytes and renal tubular cells in LN kidney biopsies correlates with fibrotic changes and impaired renal function. Characterization of senescent cells in a larger cohort of LN biopsies is ongoing. Our observations are in line with the hypothesis that inflammation-accelerated senescence links the presence of activated adaptive immune effectors in the lupus kidney and the development of fibrosis.

\section{P103 ABERRANT DNA DAMAGE RESPONSE OF B CELL POPULATIONS IN SYSTEMIC LUPUS ERYTHEMATOSUS}

${ }^{1}$ Theodora Manolakou, ${ }^{1}$ Aggelos Banos, ${ }^{1}$ Anastasia Filia, ${ }^{1,2}$ Antigone Pieta, ${ }^{1}$ Panayotis Verginis, ${ }^{1,2}$ Dimitrios Boumpas. 'Laboratory of Autoimmunity and Inflammation, Biomedical Research Foundation of the Academy of Athens, Athens; ${ }^{2}$ Rheumatology and Clinical Immunology Unit, 'Attikon' University Hospital, Athens, Greece

10.1136/lupus-2020-eurolupus. 147
Background SLE patients demonstrate increased levels of DNA damage, defective DNA repair and polymorphisms in genes required for maintaining genomic stability. Effective DNA damage response is crucial for the generation of antibodies by $\mathrm{B}$ cells while excessive production of autoantibodies is a universal feature of the disease. We sought to investigate DNA damage response/repair a) in total B cells and their subtypes in several tissues of a murine SLE model and b) in transcriptomic data derived by $\mathrm{B}$ cell subtypes from the peripheral blood of SLE patients.

Methods Flow Cytometry analysis was performed for total B cells or their subtypes combined with $\gamma \mathrm{H} 2 \mathrm{AX}$ DNA damage marker in blood, spleen, lymph nodes and bone marrow (BM) of NZBW/F1 murine SLE model (pre-diseased, $n=5 /$ diseased, $\mathrm{n}=4)$ and in the blood of SLE patients $(\mathrm{n}=7)$ compared to healthy controls ( $\mathrm{HC}, \mathrm{n}=9)$. Gene set enrichment analysis (GSEA) was performed in a published B cell populations transcriptomic dataset ${ }^{1}$ derived from the blood of SLE patients $(n=9)$ compared to HC $(n=12)$.

Results Increased $\gamma \mathrm{H} 2 \mathrm{AX}$ expression was identified in $\mathrm{B}$ cells from blood and $\mathrm{BM}$ of diseased mice compared to pre-diseased $(p=0.02)$ as well as from blood of SLE patients with high disease activity compared to HC $(p=0.02)$. Deregulated $\gamma \mathrm{H} 2 \mathrm{AX}$ expression levels were detected in distinct B subtypes of diseased mice $(\mathrm{p}<0.05)$. GSEA showed significant enrichment of DNA damage response/repair pathways in B subtypes from the blood of SLE patients compared to HC (table 1).

\begin{tabular}{|c|c|}
\hline B CELL SUBTYPE & $\begin{array}{l}\text { GENE ONTOLOGY PROCESSES \& PATHWAYS RELATED TO } \\
\text { DNA DAMAGE RESPONSE \& REPAIR (GSEA, FDR }<0.25 \text { ) }\end{array}$ \\
\hline $\begin{array}{l}\text { Resting Naive } \\
\left(\mathrm{CD} 19^{+} \lg \mathrm{D}^{+} \mathrm{CD} 27^{-} \mathrm{MTG}^{-}\right. \\
\left.\mathrm{CD} 24^{+} \mathrm{CD} 38^{+}\right)\end{array}$ & $\begin{array}{l}\text { - DNA DAMAGE RESPONSE SIGNAL TRANSDUCTION BY } \\
\text { P53 CLASS MEDIATOR } \\
\text { - INTRINSIC APOPTOTIC SIGNALING PATHWAY IN } \\
\text { RESPONSE TO DNA DAMAGE } \\
\text { - NUCLEOTIDE EXCISION REPAIR PREINCISION COMPLEX } \\
\text { STABILIZATION } \\
\text { - G2M CHECKPOINT } \\
\text { - MISMATCH REPAIR }\end{array}$ \\
\hline $\begin{array}{l}\text { Transitional } 3 \\
\left(\mathrm{CD} 19^{+} \operatorname{lgD}{ }^{+} \mathrm{CD} 27^{-} \mathrm{MTG}^{+}\right. \\
\left.\mathrm{CD} 24^{\mathrm{mid} /+} \mathrm{CD} 38^{-}\right)\end{array}$ & $\begin{array}{l}\text { - ATM PATHWAY } \\
\text { - G2M CHECKPOINT } \\
\text { - BASE EXCISION REPAIR AP SITE FORMATION } \\
\text { - DNA DAMAGE TELOMERE STRESS INDUCED } \\
\text { SENESCENCE }\end{array}$ \\
\hline $\begin{array}{l}\text { Activated Naive } \\
\left(\mathrm{CD} 19^{+} \operatorname{lgD}{ }^{+} \mathrm{CD} 27^{-} \mathrm{MTG}^{+}\right. \\
\left.\mathrm{CD} 24^{-} \mathrm{CD} 38^{-}\right)\end{array}$ & $\begin{array}{l}\text { - G2M CHECKPOINT } \\
\text { - GENOTOXIC DAMAGE 4HR }\end{array}$ \\
\hline $\begin{array}{l}\text { Isotype-Switched Memory } \\
\left(\mathrm{CD} 19^{+} \operatorname{lgD} \mathrm{D}^{-} \mathrm{CD} 27^{+}\right)\end{array}$ & $\begin{array}{l}\text { - CELL CYCLE CHECKPOINT } \\
\text { - G2 DNA DAMAGE CHECKPOINT } \\
\text { - DNA REPAIR }\end{array}$ \\
\hline $\begin{array}{l}\text { Double-Negative } \\
\left(\mathrm{CD}^{-} 9^{+} \operatorname{lgD} \mathrm{D}^{-} \mathrm{CD} 27^{-} \mathrm{CXCR5}^{-}\right)\end{array}$ & $\begin{array}{l}\text { - BASE EXCISION REPAIR } \\
\text { - NUCLEOTIDE EXCISION REPAIR } \\
\text { - MISMATCH REPAIR } \\
\text { - DNA REPLICATION }\end{array}$ \\
\hline
\end{tabular}

Conclusions NZBW/F1 murine SLE model presents with increased DNA damage in blood- and BM-derived total B cells and subtypes. Peripheral B cells and distinct B subpopulations show aberrant DNA damage response and repair in SLE patients. 
Acknowledgements ERC (No. 742390).

\section{REFERENCE}

1. Scharer, Christopher D., et al. 'Epigenetic programming underpins B cell dysfunction in human SLE.' Nature immunology 2019; 20.8; 1071-1082.

\section{P104 CORRELATION BETWEEN INTERSTITIAL CD8+ T CELL INFILTRATION AND FIBROTIC PROCESSES IN A MOUSE MODEL OF LUPUS NEPHRITIS}

\begin{abstract}
1,2Pauline Montigny, ${ }^{1}$ Aurélie Degroof, ${ }^{3}$ Davide Brusa, ${ }^{1,4}$ Frédéric Houssiau, ${ }^{1,4}$ Bernard Lauwerys. 'Pôle de Pathologies Rhumatismales Systémiques et Inflammatoires, UCLouvain, Louvain; ${ }^{2}$ Service de Rhumatologie, CHU UCL Namur, Yvoir; ${ }^{3}$ Plateforme de Cytométrie de Flux, Institut de Recherche Expérimentale et Clinique, UCLouvain, Louvain; ${ }^{4}$ Service de Rhumatologie, Cliniques Universitaires Saint Luc, Bruxelles, Belgium
\end{abstract}

10.1136/lupus-2020-eurolupus. 148

Background Tubulo-intersitial damage during lupus nephritis (LN) is associated with poor renal prognosis in the long run. Here, we describe the progression of tubulo-interstitial fibrosis and immune cells infiltration with emphasis on CD8 $+\mathrm{T}$ cells, in parallel with renal outcomes in a mouse lupus model.

Methods We collected blood, urine and kidneys from 39 B6/ Sle1.Sle2.Sle3 lupus-prone mice, before disease onset and at different stages of disease progression. RNA was extracted from kidneys and hybridized on Mouse Gene 2.0 ST exon arrays. Histopathological scores (NIH Activity and Chronicity Indexes) and digital quantification of fibrosis, IgGK deposits, $\mathrm{CD} 8+$ and $\mathrm{CD} 3+\mathrm{T}$ cells were performed on total kidney. Renal CD8 $+\mathrm{T}$ cell phenotypes were determined by flow cytometry. Plasma urea and albuminuria were measured by immunoenzymatic assays.

Results IgGK deposits, CD8 $+\mathrm{T}$ cell infiltration and interstitial fibrosis increase with the progression of renal disease, evaluated by histopathological scores and plasma urea. Further, digital quantifications allowed us to identify a significant correlation $(\mathrm{r}=0,45, p=0,011)$ between local CD8 $+\mathrm{T}$ cell population and fibrosis, while total $\mathrm{CD} 3+$ cells population and IgGK deposits did not display such association. Moreover, characterization of $\mathrm{CD} 8+\mathrm{T}$ cell subpopulations showed that fibrosis is more specifically linked to effector functions of $\mathrm{CD} 8+\mathrm{T}$ cells. Transcriptomic analyses supported this association, with a high correlation coefficient between mean expression of effector functions transcripts and the presence of a fibrotic signature $(r=0,92, p<0,0001)$.

Conclusions Our results support the association between CD8 $+\mathrm{T}$ cell tubulo-interstitial infiltration and renal outcomes in a mouse lupus model. Further, a strong correlation is identified between effector functions of CD8 $+\mathrm{T}$ cells and fibrotic processes, opening new avenues of research in the pathogenesis of $\mathrm{LN}$.

Acknowledgements This work was supported by F.R.S-F.N.R.S and by Fondation Roi Baudouin.

\section{P105 EXPRESSION DIVERSITY OF INTERFERON-STIMULATED GENES IN PERIPHERAL BLOOD CELLS FROM PATIENTS WITH SYSTEMIC LUPUS ERYTHEMATOSUS}

Kanwal Siddiqi, Søren Jacobsen. Copenhagen Lupus and Vasculitis Clinic, Rigshospitalet, Copenhagen University Hospital, Copenhagen, Denmark

10.1136/lupus-2020-eurolupus. 149
Background A central facet of the immunopathogenesis of systemic lupus erythematosus (SLE) is the activation of interferon (IFN) signalling. In SLE patients, several types of IFNs are upregulated as well as the genes that are stimulated by IFNs. Sustained expression of interferon-stimulated genes (ISGs) may have adverse effects including altered $\mathrm{T}$ cell function, tissue inflammation and organ damage. The distinct association of the IFN gene signature to SLE disease activity is still uncertain.

Methods Peripheral blood samples from 34 SLE patients and 15 healthy controls were collected in PAXgene tubes. RNA from peripheral blood cells (PBCs) was extracted using the PAXgene Blood RNA Kit. The mRNA transcripts of 105 ISGs were measured using the multiplexed Nanostring nCounter Gene Expression platform. Bioinformatics and statistical analysis were performed using nSolver and SPSS.

Results We found that SLE patients had significantly higher expression levels of a wide range of ISGs, as compared to healthy controls. The 5 most upregulated ISGs in PBCs were IFI27, IFI44L, USP18, RSAD2 and ISG15. Using principal component analysis we identified two subsets of ISGs of which one included the mentioned top-five expressed ISGs; this gene cluster consisted of ISGs with predominantly antiviral functions and STAT1/STAT2, and did not associate with clinical disease activity or history of nephritis in SLE patients. Instead these genes associated with anti-SSA/SSB antibodies and PBC expression of PDCD1 and LAG3, which are markers of CD8 $\mathrm{T}$ cell exhaustion. The second group of ISGs associated with clinical disease activity, STAT3 and NFKB expression.

Conclusions Our results indicate the presence of ISG subsets that are differentially associated to clinical, serological and immunological features of SLE. Thus, the IFN gene signature in SLE may consist of a highly complex network of ISGs that can be clustered, and each in their way contribute to the pathogenesis of SLE. Also, this challenges the construction IFN gene signatures and scores with respect to what purpose they are intended for.

\section{P106 PENTAMERIC, BUT NOT MONOMERIC C-REACTIVE PROTEIN, LIMITS THE SNRNP-IMMUNE COMPLEX TRIGGERED TYPE I INTERFERON RESPONSE: IMPLICATIONS FOR LUPUS PATHOGENESIS}

${ }^{1}$ Cecilia Svanberg, ${ }^{1}$ Helena Enocsson, ${ }^{1}$ Klara Martinsson, ${ }^{2}$ Lawrence Potempa, ${ }^{2}$ Ibraheem Rajab, ${ }^{1}$ Jonas Wetterö, ${ }^{1}$ Marie Larsson, ${ }^{1}$ Christopher Sjöwall. 'Linköping University, Linköping, Sweden; ${ }^{2}$ Roosevelt University, Chicago, USA

10.1136/lupus-2020-eurolupus. 150

Background Systemic Lupus Erythematosus (SLE) is an autoimmune systemic disease affecting multiple organs and which is characterized by autoantibodies directed against nuclear constituents. Common autoantibody targets include doublestranded (ds) DNA and small nuclear ribonucleoproteins (snRNPs; i.e. U1-snRNP). Uptake of immune complexes (ICs) by plasmacytoid dendritic cells ( $\mathrm{pDCs}$ ) can activate endosomal toll-like receptors (TLRs) such as TLR-7 and TLR-9 if nucleic acids are present in the ICs. Such activation is dependent on IC internalization by $\mathrm{Fc} \gamma$ receptor type IIa (Fc $\gamma$ RIIa), and results in production of type I interferons (IFNs), a hallmark of SLE and a target for therapeutic interventions. The acute phase protein C-reactive protein (CRP) 